\title{
GMR
}

\section{Effect of all-trans retinoic acids (ATRA) on the expression of $\alpha$-smooth muscle actin ( $\alpha-S M A)$ in the lung tissues of rats with pulmonary arterial hypertension (PAH)}

\author{
Y. Xin ${ }^{1}$, J.-Q. Lv' ${ }^{1}$ Y.-Z. Wang ${ }^{2}$, J. Zhang ${ }^{1}$ and X. Zhang ${ }^{1}$ \\ 1'Department of Pediatrics, Affiliated Hospital of Jiangsu University, Zhenjiang, China \\ ${ }^{2}$ Department of Pathology, Medical School of Jiangsu University, Zhenjiang, China
}

Corresponding author: J.-Q. LV

E-mail: ljquan2015@163.com

Genet. Mol. Res. 14 (4): 14308-14313 (2015)

Received May 26, 2015

Accepted August 6, 2015

Published November 13, 2015

DOI http://dx.doi.org/10.4238/2015.November.13.15

ABSTRACT. The effect of all-trans retinoic acid (ATRA) on the expression of $\alpha$-smooth muscle actin ( $\alpha$-SMA) in rats with pulmonary arterial hypertension (PAH) was studied, and the mechanism of the effect of ATRA on PAH was proposed. Thirty male SD rats were randomly divided into normal control, monocrotaline (MCT) model, and ATRA [30 mg/(kg.day)] intervention groups ( $\mathrm{N}=10$ each). The mean pulmonary arterial pressure was recorded. Right ventricular hypertrophy index $(\mathrm{RVHI})$ was calculated (weight of right ventricle: total weight of left ventricle and interventricular septum). The percentages of wall thickness of pulmonary arteriole (WT) to external diameter of artery (WT\%) and vascular wall area (WA) to total vascular area (WA\%) were determined. Real-time fluorescencebased quantitative PCR and western blot analyses were employed to detect the a-SMA mRNA and protein expressions. The mean pulmonary arterial pressure, RVHI, WT\%, and WA\% were all obviously higher in the model group than in the control and intervention groups. The values of these indicators in the intervention group were also higher than those in the control group $(P<0.01)$. The mRNA and protein expression levels of 
a-SMA were significantly higher in the lung tissue of model rats than those in the control and intervention groups. However, the intervention group showed no statistically significant differences in a-SMA mRNA and protein expression levels compared to the control $(P<0.05)$. ATRA inhibited the $\alpha-S M A$ mRNA and protein expressionin the lung tissues of rats with MCTinduced $\mathrm{PAH}$, and could be used to treat $\mathrm{PAH}$.

Key words: Pulmonary arterial hypertension, All-trans retinoic acid; Monocrotaline, a-Smooth muscle actin

\section{INTRODUCTION}

Pulmonary arterial hypertension (PAH) is an increase in blood pressure in the pulmonary artery, pulmonary vein, or pulmonary capillaries, which can result in right ventricular failure and death. Retinoids are natural and synthetic derivatives of vitamin A, and play an important role in cell proliferation and differentiation. Many biological functions are associated with vascular reconstruction in $\mathrm{PAH}$. PAH was induced in rats using monocrotaline (MCT) to observe the effect of ATRA on PAH. In this study, the levels of expression of $\alpha$-smooth muscle actin ( $\alpha-S M A)$ were detected in lung tissues, and the mechanism with which ATRA affects the prevention and treatment of PAH was analyzed.

\section{MATERIAL AND METHODS}

\section{Experimental animals, reagents and instruments}

Healthy male Sprague-Dawl (SD) rats weighing $220 \pm 20 \mathrm{~g}$ were provided by the Experimental Animal Center of the Medical School of Jiangsu University. The reagents utilized in this study included MCT (Sigma-Aldrich, USA), ATRA (Northeast Pharmaceutical Co., Ltd.), TRIzol reagent (Invitrogen, USA), reverse transcription kit (Toyoba, Shanghai, China), and the fluorescence quantitative kit (Toyoba). $\alpha$-SMA mRNA primers were synthesized by Sangon Biotech (Shanghai, China). The Medlab-E Biology Gathering System used in this study was manufactured by the Nanjing Meiyi Technology Co., Ltd.

\section{Model establishment and grouping}

Thirty SD rats were randomly divided into the control, model, and intervention groups, with 10 rats in each group. MCT was injected into the model and intervention groups to induce PAH. MCT was dissolved in appropriate quantities of $0.5 \mathrm{~N} \mathrm{HCl}$, and the $\mathrm{pH}$ value was adjusted to 7.4 using $0.5 \mathrm{~N} \mathrm{NaOH}$. Intraperitoneal injection $(60 \mathrm{mg} / \mathrm{kg}$ ) was performed once for the model and intervention groups. Equal volumes of normal saline was injected into rats of the control group. Gastric lavage was performed once every day between days 0 and 28 of the experiment using ATRA (30 mg/kg.day) and normal saline, for the intervention and model groups, respectively.

\section{Preparation of pulmonary artery catheter}

PV-1 tube (length approximately $15 \mathrm{~cm}$ ) was used as the artery catheter. The tube was heated using a flame at a distance of $1 \mathrm{~cm}$ from one end, in order to make it bend towards the heat 
(under the effect of gravity). A smooth arc was obtained with a radius of approximately $3 \mathrm{~cm}$, and the curvature comparable to that of the right ventricular wall and pulmonary artery. The catheter was marked 3-4 cm from one end in order to track the position of the catheter.

\section{Measurement of mean pulmonary arterial pressure and RVHI}

After treatment for 28 days, the rats were anesthetized by intraperitoneal injection of $3 \%$ sodium pentobarbital $(30 \mathrm{mg} / \mathrm{kg})$, and immobilized in the supine position. An incision was made to the right of the midline of the neck to expose and dissociate the right external jugular vein. The pulmonary artery catheter, filled with heparin saline, was inserted into the right external jugular vein. The arc was made to point downwards during the insertion. Upon reaching the heart, the catheter was rotated towards the left and advanced further. Following the increase in the baseline pressure and the appearance of the pulmonary artery pressure waveform on the physiological grapher, the catheter was retracted by about $1 \mathrm{~cm}$. The catheter was advanced again until the mean pulmonary artery pressure waveform was observed (Wang et al., 2000; Wang, 2003). The heart was harvested after measurement of this waveform. The atria were removed, and the left ventricle, right ventricle, and interventricular septum were separated. The tissues were washed with iced saline, dried with filter paper, and weighed. RVHI was measured.

\section{Preparation of tissue specimens and detection of indicators}

The rats were sacrificed. The lower lobe of the right lung was harvested and fixed in $10 \%$ formaldehyde. The tissues were made into paraffin sections and subjected to hematoxylinEosin (HE) staining. The pulmonary arterioles, with s diameter of 50-100 $\mu \mathrm{m}$, were then randomly selected in each field of view. The wall thickness (WT) and external diameter (ED) was measured using a pathological image analysis software. WT\% (WT\% $=2 \times($ WT/ED) $\times 100)$ and WA $\%$ [WA $\%$ $=(T A-L A) / T A \times 100]$ were calculated.

\section{Detection of mRNA and protein expression of $\alpha$-SMA in lung tissues by fluorescent quantitative RT-PCR}

The lower lobe of the left lung, weighing $0.1 \mathrm{~g}$, was harvested for total RNA extraction by the one-step method, according to the TRIzol reagent manufacturer protocols. cDNA reverse transcription was performed for the cytokines using $1 \mathrm{~mL}$ of the RNA extracted from each sample, according to the standard protocols provided in the reverse transcription kit. The specific primers of a-SMA (with primers for beta-actin acting as the internal reference) were used for DNA amplification. The primer sequences were as follows: $\alpha$-SMA (168 bp), 5'-ATAGAACACGGCATCATCACC -3', 5'-GGTCTCAAACATAATCTGGGTCA-3'; BETA-ACTIN (207 BP), 5'-CACCCGCGAGTACAAC CTTC-3', 5'-CCCATACCCACCATCACACC-3'. The PCR reaction conditions were set as follows: pre-denaturation at $95^{\circ} \mathrm{C}$ for $5 \mathrm{~min}, 40$ cycles of denaturation at $95^{\circ} \mathrm{C}$ for $15 \mathrm{~s}$, annealing at $56^{\circ} \mathrm{C}$ for $30 \mathrm{~s}$, and extension at $72^{\circ} \mathrm{C}$ for $30 \mathrm{~s}$, and a final extension at $72^{\circ} \mathrm{C}$ for $10 \mathrm{~min}$.

The lower lobe of the left lung, weighing $0.1 \mathrm{~g}$, was washed twice with pre-cooled PBS buffer. Then, $1.5 \mathrm{~mL}$ of the protein lysis buffer and $15 \mu \mathrm{L}$ of the protease inhibitor was added. The cells were scraped off and lysed on ice at $4^{\circ} \mathrm{C}$ for $20 \mathrm{~min}$. Following centrifugation at $15000 \mathrm{rpm}$ for $15 \mathrm{~min}$, the supernatant was collected and mixed with the loading buffer. The cells were denatured by heating in a $100^{\circ} \mathrm{C}$ water bath for $5 \mathrm{~min}$. Thirty milligram of protein was collected for each group to 
perform SDS-PAGE analysis. The proteins were transferred to a nitrocellulose membrane and sealed with $5 \%$ defatted milk powder at room temperature for $1 \mathrm{~h}$. The cells were further incubated overnight with primary antibodies at $4^{\circ} \mathrm{C}$, followed by incubation with secondary antibodies at room temperature for $1 \mathrm{~h}$. The membranes were developed using an electrochemiluminescent (ECL) solution.

\section{Statistical analysis}

All experimental data were expressed as mean \pm standard deviation (SD). Thestatistical analyses were performed using SPSS software. Multi-group comparisons were made by ANOVA and $\mathrm{P}<0.05$ was considered to be statistically significant.

\section{RESULTS}

\section{Mean pulmonary arterial pressure and RVHI of rats in each group}

The mean pulmonary arterial pressure of rats in the model group was significantly higher than that in the control and intervention groups $(P<0.01)$. The intervention and control groups also differed in mean pulmonary arterial pressure and RVHI $(P<0.01$, Table 1$)$.

\section{Morphological observation of pulmonary arterioles}

The morphological indicators of pulmonary vessels were compared. We observed an obvious thickening of the walls of the pulmonary vessels, and narrowing of lumens, following MCT treatment for 28 days. The extent of such morphological variations was much lower in the intervention group compared to the MCT group. The endothelial cells of pulmonary vessels showed better continuity in the control group (Table 1 and Figure 1).

Table 1. Comparison of mean pulmonary arterial pressure, right ventricular hypertrophy index (RVHI), and morphological indicators of pulmonary vessels between the groups (mean $\pm \mathrm{SD}$ ).

\begin{tabular}{lcccrr}
\hline Group & $\mathrm{N}$ & Mean pulmonary arterial pressure $(\mathrm{mmHg})$ & RVHI $(\mathrm{g})$ & WT $(\%)$ & WA $(\%)$ \\
\hline Model group & 10 & $29.91 \pm 1.16^{\mathrm{a}}$ & $0.51 \pm 0.08^{\mathrm{a}}$ & $55.7 \pm 8.00^{\mathrm{a}}$ & $67.5 \pm 3.94^{\mathrm{a}}$ \\
Intervention group & 10 & $22.52 \pm 0.97$ & $0.35 \pm 0.02^{\mathrm{b}}$ & $32.5 \pm 2.65^{\mathrm{b}}$ & $50.3 \pm 3.10^{\mathrm{b}}$ \\
Control group & 10 & $16.23 \pm 0.78$ & $0.24 \pm 0.01$ & $21.70 \pm 1.47$ & $37.00 \pm 2.28$ \\
F & & 143.33 & 72.00 & 123.93 & 232.47 \\
$\mathrm{P}$ & & 0.00 & 0.00 & 0.00 & 0.00 \\
\hline
\end{tabular}

Compared to the other groups, a $\mathrm{P}<0.01$; compared to the control, ${ }^{\mathrm{b}} \mathrm{P}<0.01$.
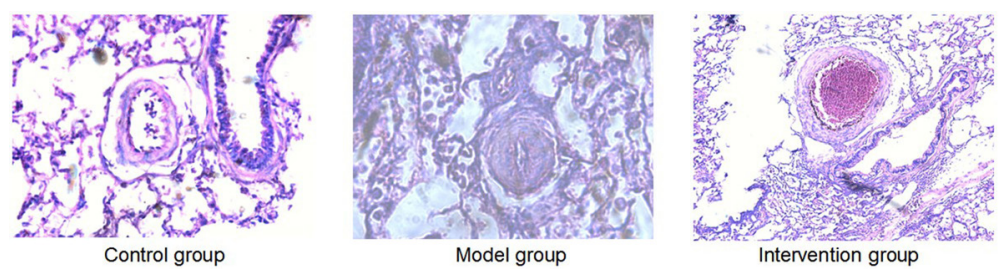

Figure 1. Morphological observation of pulmonary arterioles by hematoxylin-Eosin (HE) staining in rats of each group (400X). Model group: Obvious thickening of the walls of the pulmonary arterioles and narrowing of the lumen; Intervention group: Extent of wall thickening of pulmonary arterioles and narrowing of lumen was much lower than that seen in the MCT group; Control group: The endothelial cells of pulmonary vessels displayed better continuity. 


\section{mRNA and protein expressions of $\alpha$-SMA in lung tissues}

The mRNA and protein expressions of $\alpha$-SMA in the lung tissues were analyzed by RT$\mathrm{PCR}$, using beta-actin as the internal reference. The results are summarized in Table 2 and Figure 2. The mRNA expression of $\alpha-S M A$ in the model group was much higher than that in the intervention and control groups $(P<0.01)$. The intervention group did not differ significantly from the control group in terms of $\alpha-S M A$ mRNA expression in the lung tissues $(P<0.01)$. The results in Figure 2 were consistent with those in Table 2.

Table 2. Comparison of relative mRNA expression of $\alpha-S M A$ between the groups (mean $\pm S D$ ).

\begin{tabular}{llr}
\hline Group & $\mathrm{N}$ & $\mathrm{a}-\mathrm{SMA}\left(2^{-\Delta \mathrm{CC}}\right)$ \\
\hline Model group & 10 & $4.42 \pm 2.05^{\mathrm{a}}$ \\
Intervention group & 10 & $1.20 \pm 0.52^{\mathrm{b}}$ \\
Control group & 10 & 1 \\
F & & 24.77 \\
$\mathrm{P}$ & & 0.00 \\
\hline
\end{tabular}

Compared with other groups, a $\mathrm{P}<0.01$; compared with the control, ${ }^{\mathrm{b}} \mathrm{P}>0.05$.

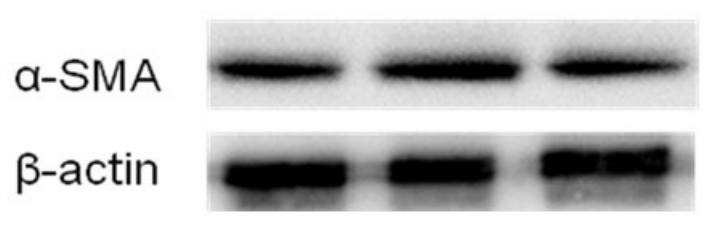

Control group Model group Intervention group

Figure 2. Expression levels of $\alpha$-SMA in rats of each group.

\section{DISCUSSION}

$\mathrm{PAH}$ is a clinical syndrome featuring right ventricular failure, induced by persistent increase in pulmonary vascular resistance under the impact of a variety of pathogenic factors. Different types of vessels and cytokines in the pulmonary tissues play a key role in the pathogenesis of PAH.

In our study, the PAH model was established in rats using MCT. MCT, a bisbenzylisoquinoline alkaloid, is activated by cytochrome P450 monooxygenase into monocrotalinepyrrole (MCTP), and then transported to the liver by blood circulation. MCT induces hypertrophic pulmonary vasculitis and PAH by effecting a vascular endothelial injury (Stenmark et al., 2005; Kamezaki et al., 2008). Single injection of MCT leads to hypertrophy of the pulmonary arterial media, $\mathrm{PAH}$, right ventricle (RV) pressure overload, and finally thickening of the RV. Therefore, the PAH model is usually induced by MCT injection in rats (Liang et al., 2010). We observed a significant rise in mean pulmonary arterial pressure with ventricular hypertrophy 4 weeks after MCT injection, indicating the successful establishment of the PAH model.

Vascular adventitial fibroblasts in resting state can be transformed into myoblasts (MB) under the action of pathogenic factors, which then migrate to the intima and participate in neonatal intima formation. MB features contractility and a special structure, intermediate between that of fibroblasts and smooth muscle cells (Kapanci et al., 1992). During proliferation, MB synthesizes a 
large amount of extracellular matrix (ECM). The enhanced secretion of cytokines, growth factors, and inflammatory mediators facilitates the transformation of the fibroblasts into $M B$, which is involved in pulmonary vascular remodeling. Moreover, a-SMA is a marker of MB. Previous research (Short et al. 2004) has shown that hypoxia induces the transformation of fibroblasts into MB by upregulating a-SMA. The active role of $\alpha-S M A$ was also confirmed in PAH.

ATRA, a derivative of vitamin A, inhibits cell proliferation and promotes cell differentiation. Currently, ATRA has been effectively used in anti-cancer treatment strategies (Wiegman et al., 2000), and against skin diseases caused by epithelial proliferation (Pakala et al., 1995). Therefore, ATRA has drawn the attention of researchers because of its efficacy in the treatment of vascular obstructive diseases (Braunhut et al., 1994). So far, very few studies have reported the intervention of pulmonary vascular reconstruction in PAH using ATRA (Qin et al., 2000).

Our findings indicate that ATRA could inhibit the mRNA and protein expression of $\alpha$-SMA in MCT-induced PAH. The mean pulmonary arterial pressure was decreased and ventricular hypertrophy was alleviated after 4 weeks of ATRA treatment. Pathological specimens of lung tissues showed the thinned walls and enlarged lumen of the pulmonary arteriole. The WT\% and WA $\%$ values were significantly decreased in the intervention group compared to the model group. ATRA, at a certain concentration, regulates cell growth, proliferation, differentiation, maturity, and apoptosis (Bushue et al., 2010). Due to its multiplicity of biological functions, ATRA is widely used to treat tumors and skin diseases; in addition, its effect on the cardiovascular, immune, and nervous systems is currently being explored. Although the role of ATRA in vascular remodeling has been reported in PAH, the precise mechanism of action remains unknown. We discovered that treatment with ATRA was effective against $\mathrm{PAH}$, as it inhibited vascular remodeling by downregulation of $\alpha$-SMA.

\section{REFERENCES}

Braunhut SJ and Moses MA (1994). Retinoids modulate endothelial cell production of mat rix-degrading proteases and tissue inhibitors of metallo-proteinases (TIMP). J. Biol. Chem. 269: 13473-13479.

Bushue N and Wan YJ (2010). Retinoid pathway and cancer therapeutics. Adv. Drug Deliv. Rev. 62: 1285-1298.

Kamezaki F, Tasaki H, Yamashita K, Tsutsui M, et al. (2008). Gene transfer of extracellular superoxide dismutase ameliorates pulmonary hypertension in rats. Am. J. Respir. Crit. Care Med. 177: 219-226.

Kapanci Y, Ribaux C, Chaponnier C and Gabbiani G (1992). Cytoskeletal features of alveolar myofibroblasts and pericytes in normal human and rat lung. J. Histochem. Cytochem. 40: 1955-1963.

Liang C, Jin HF, Du SX and Du JB (2010). Changes of Type I collagen in pulmonary arteries of rats with monocrotaline-induced pulmonary hypertension. J. Appl. Clin. Ped. 25: 18-20.

Pakala R, Davies PJA and Chandraratna R (1995). All trans-Retinoic acid and its derivatrives inhibit serotonin induced vascular smooth muscle cell proliferation. J. Am. Coll. Cardiol. 15: 83A-84A.

Qin YM, Zhou AQ, Shen J, Ben XM, et al. (2000). Experimental study of all-trans retinoic acid intervention in lung tissue of pulmonary hypertension. China Modern Med. Res. 10: 8-9.

Short M, Nemenoff RA, Zawada WM, Stenmark KR, et al. (2004). Hypoxia induces differentiation of pulmonary artery adventitial fibroblasts into myofibroblasts. Am. J. Physiol. Cell Physiol. 286: 416-425.

Stenmark KR and Mcmurtry IF (2005). Vascular remodeling versus vasoconstriction in chronic hypoxic pulmonary hypertension: A time for reappraisal. Circ. Res. 97: 95-98.

Wang JY, Wang HL, Zhang XH and Xing J (2000). Effects of Peucedanum Praeruptorum Dunnon on the monocrotalineinduced pulmonary hypertension in rats. Chin. Pharmaceut. J. 35: 90-93.

Wang HL (2003). Rotonin receptor as a potential therapeutic target for pulmonary vascular remodeling. Drug Develop. Res. 56: 4-10.

Wiegman PJ, Barry WL, McPherson JA, McNamara CA, et al. (2000). All-trans-retinoic acid limits restenosis after balloon angioplasty in the focally atherosclerotic rabbit: a favorable effect on vessel remodeling. Arterioscler. Thromb. Vasc. Biol. 20: 89-95. 